\title{
ECOLOGY
}

DOI https://doi.org/10.30525/978-9934-26-183-1-6

\section{ANALYTICAL DESCRIPTION OF THE CHANGE IN THE ACTIVATION ENERGY OF LITHOSPHERE ELEMENTS DURING THEIR DEFORMATION}

\author{
Bakhtyn A. I. \\ PhD-student at the Department of Ecology and Plant Polymers Technology \\ National Technical University of Ukraine \\ «Igor Sikorsky Kyiv Polytechnic Institute» \\ Kryuchkov A. I. \\ Candidate of Technical Sciences, \\ Associate Professor at the Department of Geo-Engineering \\ National Technical University of Ukraine \\ «Igor Sikorsky Kyiv Polytechnic Institute» \\ Kyiv, Ukraine
}

Drilling and blasting operations in quarries are always accompanied by significant energy losses of the explosion, which significantly exceed the share of its useful effect. This energy, as a rule, enters the elements of the lithosphere and is spent on deformation of rocks, changes in relief, the formation of cracks and voids. This fact is explained by the very nature of the explosion, ie a significant loss of potential energy.

Development of analytical physical and technical bases of energy destruction of rock massif, at external impulse or static loading, will allow to achieve at the applied level of effective controllability of energy flows in the process of mass explosions.

In most cases, the description of the dependence of stress on deformation is carried out by the methods of piecewise linear approximation, and areas of pre-boundary and out-of-boundary stress are considered as linear dependences. In practice, experimental studies have shown that this approach is not fully true, which leads to the accumulation of errors in calculations. 
The purpose of this article is to establish analytical patterns for predicting changes in stresses and densities of energy spent on the destruction of rocks according to experimental studies.

To verify the analytical description of the complete diagram of deformation and fracture energy density, the data of experimental measurements [1].

During an explosion or other action of external forces, the rock massif changes its shape, size, volume, ie deforms. Deformation is a change in the relative position of a particle of rock or other solid system that causes a change in the volume or shape of the sample.

Deformations that appear only at the moment of applied load are called instantaneous-elastic, and deformations that develop over time are called creep deformations.

At the rigid mode of loading the maximum bearing capacity of the sample $\sigma_{\mathrm{c}}$ corresponds to the limit of instantaneous strength of the rock mass on uniaxial compression $\sigma_{\mathrm{c}}{ }^{*}[2,3]$.

A further increase in the deformation $\varepsilon_{\mathrm{ij}}$ leads to a gradual decrease in the bearing capacity of the sample to the minimum value $\sigma_{\min }$, which is called the residual strength of the rock (Table 1). The construction of such complete load diagrams is possible only in the rigid load mode, when the intensity of the impact exceeds the stiffness of the sample. The simplest method of research in this mode [2] is to construct deformation curves in the form of cyclic loads on equipment equipped with deformation limiters in the form of rigid stops. The curve that encircles the individual diagrams of loading and unloading gives a complete diagram of the deformation and destruction of rock in preboundary and out-of-boundary areas of load (Table 1).

Table 1

Complete deformation diagram of siltstone sample [1]

\begin{tabular}{|c|c|c|c|c|c|c|c|c|c|}
\hline $\begin{array}{c}\sigma_{11}, \\
\mathrm{MPa}\end{array}$ & 0 & 10 & 20 & 30 & 34 & 30 & 20 & 10 & 4 \\
\hline$\varepsilon_{11}$ & 0 & 0,003 & 0,007 & 0,01 & 0,014 & 0,018 & 0,022 & 0,028 & 0,04 \\
\hline
\end{tabular}

The results of experimental and analytical studies of complete diagrams of rock deformation suggest that the dependence of the maximum stress $\sigma_{11}$ on the deformation $\varepsilon_{11}$ can be represented as an expression:

$$
\sigma_{11}\left(\varepsilon_{11}\right)=\frac{\sigma_{\mathrm{c}}}{\alpha}\left[\exp \left(\frac{\varepsilon_{c}-\varepsilon_{11}}{\varepsilon_{T}}\right) \exp \left(-\exp \left(\frac{\varepsilon_{c}-\varepsilon_{11}}{\varepsilon_{T}}\right)\right)\right]+\sigma_{\text {min }}
$$


where $\sigma_{11}\left(\varepsilon_{11}\right)$ - the envelope function of the maximum stress during cyclic loading and unloading of the rock sample; $\varepsilon_{11}$ - variable relative deformation; $\varepsilon_{\mathrm{c}}$ - relative deformation, which corresponds to the stress $\sigma_{11}=\sigma_{\mathrm{c}} ; \varepsilon_{\mathrm{T}}$-intensity of increase and decrease of loading; $\alpha$-coefficient that depends on the type of rock.

Maximum and minimum stresses for specific rocks are constant and depend on moisture, mineralization and morphological structure.

Estimated parameters for siltstone are presented in table. 2.

Using equations (1) and the obtained values of the parameters (Table 2), the values of the main stress $\sigma_{11}$ in the range of strain change from 0 to 0.04 were calculated. The results of the calculations are presented in Fig. 1, b.

Table 2

Estimated parameters for the considered rock

\begin{tabular}{|c|c|c|c|c|c|}
\hline Parameter & $\sigma_{\mathrm{c}}, \mathrm{MPa}$ & $\sigma_{\min }, \mathrm{MPa}$ & $\varepsilon_{\mathrm{c}}$ & $\varepsilon \mathrm{T}$ & $\alpha$ \\
\hline Value & 32 & 2 & 0,0133 & 0,007 & 0,37 \\
\hline
\end{tabular}

Given that the experimental points lie with a small deviation on the analytical curve (Fig. 1, b), we can conclude that the studied experimental regularity can be described by analytical dependence (1).

On the full deformation diagram (Fig. 1, b) there are a number of characteristic areas. Area $0 \mathrm{~A}$ is a segment that characterizes the closure of defects in the sample (pores, cracks). AB - area that characterizes the zone of elastic deformation. In this area there is a linear dependence of stress on deformation. Plastic deformations and cracks occur on the segment BD. Point $\mathrm{C}$ corresponds to the maximum stress in the sample and characterizes the maximum resistance of the rock to fracture.

Point $\mathrm{C}$ corresponds to the maximum stress in the sample and characterizes the maximum resistance of the rock to fracture. Along with the elastic ones, plastic deformations are always observed to a greater or lesser extent.

When studying a sample of rock for uniaxial compression $\left(\sigma_{2}=\sigma_{3}=0\right)$ the minimum resistance to destruction $\sigma_{\min }$ is close to zero (Fig. 1, a). This mode of research allows to obtain the basic parameters of the dependence $\sigma_{11}=\mathrm{f}\left(\varepsilon_{11}\right)$, such as $\mathrm{U}_{\mathrm{c}}, \mathrm{U}_{0}$. 


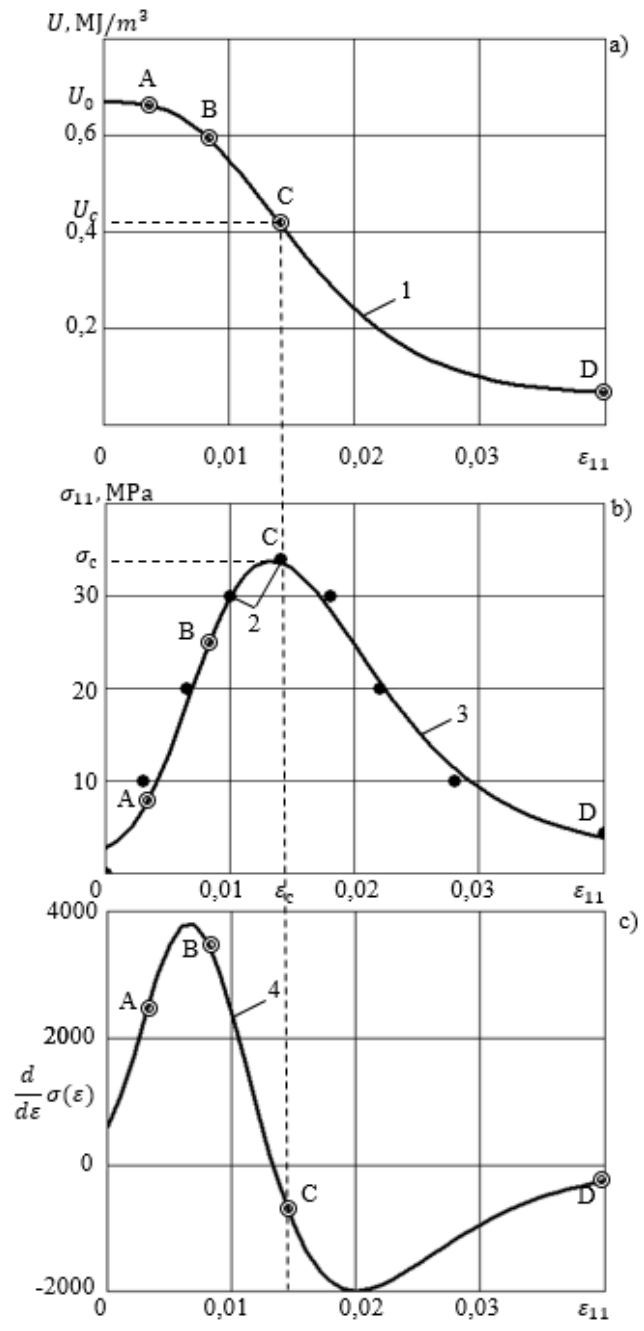

Fig. 1. Energy diagram (a) of the deformation of the siltstone sample and the complete diagram of the change in stress (b): 1 - analytical curves of energy deformation according to equation (3); 2 - experimental values of siltstone stresses; 3 - analytical regularity of the dependence of the principal stress on the principal deformation, equation (1); 4 -derived from the principal stress depending on the principal deformation 
To do this, determine the volumetric energy density spent on the destruction of the rock sample by integrating expression (1) (Fig. 1, a):

$$
U\left(\varepsilon_{11}\right)=\int_{0}^{\varepsilon_{11}} \sigma_{11}\left(\varepsilon_{11}\right) d \varepsilon_{11}
$$

After certain transformations of dependence (2) and taking the integral we obtain:

$$
U\left(\varepsilon_{11}\right)=U_{0}\left[1-\exp \left(-\exp \left(\frac{\varepsilon_{c}-\varepsilon_{11}}{\varepsilon_{T}}\right)\right)+\sigma_{\text {min }}\right]
$$

The results of integration are presented in Fig. 1, a. The maximum activation energy for siltstone is $\mathrm{u}_{0}=0.67 \mathrm{MJ} / \mathrm{m}^{3}$. A comparison of the experimental and calculated values of the energy dependence $u\left(\varepsilon_{1}\right)(3)$ shows their coincidence over almost the entire range of deformation changes $\left(\varepsilon_{1}=0 . .0,04\right)$.

Studies show that the energy density spent on deformation and destruction of rock is determined by the magnitude of the linear deformation $\varepsilon_{11}$ according to the established dependence (3).

\section{Conclusions:}

1. The curve that encircles the deformation cycles (1) combines preboundary and out-of-boundary modes of deformation and destruction of rocks.

2 . The energy curve enveloping the deformation cycles can be analytically described by expression (2), which is confirmed by experiments. Equation (3) allows us to establish that the destruction can occur at different values of energy density $\mathrm{U}(\varepsilon)$. The maximum activation energy for siltstone is $\mathrm{U}_{0}=0.67$ $\mathrm{MJ} / \mathrm{m}^{3}$.

\section{References:}

1. Баклашев И. В., Деформирование и разрушение породных массивов. Москва, 1988. 271 с.

2. Крючков А. I., Бахтин А. I. Зміна енергетичних характеристик елементів літосфери при їх деформації. Геоінженерія. 2021. № 6. C. 63-69. DOI: https://doi.org/10.20535/2707-2096.6.2021.241939

3. Баклашев И. В., Картозия Б. А., Механические процессы в породных массивах. Москва, 1991. 273 с. 